\title{
Evaluando el Nivel de Implementación de las Políticas de Infancia y Adolescencia en la Regiones Metropolitana y de Valparaíso: Una mirada a la calidad desde la complejidad municipal
}

\author{
Raúl Silva Farías * \\ Cristóbal Villalobos Dintrans ** \\ Universidad Diego Portales \\ Mahia Saracostti Schwartzman *** \\ Universidad Autónoma de Chile \\ Chile
}

Fecha recepción: 29/06/20 II

Fecha aceptación: 01/08/20I I

\section{Resumen}

El artículo presenta una evaluación del nivel de implementación de las políticas de infancia y adolescencia en los gobiernos locales de dos regiones de Chile. Se da cuenta de aspectos como los programas implementados, las planificaciones desarrolladas, las redes construidas, los recursos invertidos y la institucionalización que alcanzan estos aspectos. Posteriormente, se desarrolla un análisis multinivel que evalúa estos elementos a la luz de las condiciones municipales y la complejidad del contexto de cada comuna. Los resultados muestran que el nivel de implementación de políticas de infancia no depende de las condiciones del municipio, por lo que se releva la importancia de la voluntad política de las autoridades locales para su desarrollo.

Palabras claves: Políticas de Infancia y Adolescencia - Convención de Derechos del Niño - Políticas Municipales de Infancia y Adolescencia - Condiciones Municipales Complejidad y Calidad Municipal

Evaluating the extent of implementation of policies for children and teenagers in the metropolitan region and the Valparaiso region: a look at quality in the light of municipal complexity

\section{Abstract}

The article offers an assessment of the degree of implementation of policies towards children and teenagers in the local governments of two regions of Chile. It covers aspects such as the programmes that have been implemented, the plans that have been developed, the networks that have been built, the resources invested, and the level of 
institutionalization that has been reached for each of these areas. It then develops a multi-level analysis that evaluates these elements in the light of local conditions and the complex and unique context of each municipality. The results show that the level of implementation of policies towards children does not depend on the Socio-economic conditions of the municipality but rather reveals the importance of the level of political will of the local political authorities as an explanatory factor.

Key words: Policies towards children and teenagers; Convention on the Rights of the Child, Municipal policies for children and teenagers; Municipal conditions, Complexity and quality of municipal services.

Avaliando o nível de implementação das políticas da infância e adolescência nas regiões metropolitana e de Valparaíso: uma visão para a qualidade a partir da complexidade municipal

\section{Resumo}

O artigo apresenta uma avaliação do nível de implementação das políticas da infância e da adolescência nos governos locais de duas regiões do Chile. Mostra aspectos como os programas implementados, os planejamentos desenvolvidos, as redes construídas os recursos investidos e a institucionalização que esses aspectos obtêm. Posteriormente, desenvolve-se uma análise multinível que avalia esses elementos devido às condições municipais e à complexidade do contexto de cada bairro. Os resultados mostram que o nível de implementação de políticas da infância não depende das condições do município, portanto é relevada a importância da vontade política das autoridades locais para o seu desenvolvimento.

Palavras chave: Políticas da Infância e Adolescência, Convenção de Direitos da Criança, Políticas Municipais da Infância e Adolescência, Condições Municipais, Complexidade e Qualidade Municipal

* Sociólogo, Universidad Católica de Chile. Cursando el Magíster en Gestión y Políticas Públicas, Universidad de Chile. investigador de la Facultad de Educación de la Universidad Diego Portales.raul.silva.f@gmail.com

** Sociólogo y Trabajador Social, Universidad Católica de Chile y Magíster $\odot$ en Economía Aplicada a las Políticas Públicas, Universidad Alberto Hurtado y Georgetown University. Facultad de Educación de la Universidad Diego Portales. cristobal.villalobos@gmail.com

*** Trabajadora Social y M.B.A. de la Pontificia Universidad Católica de Chile. Ph.D. en Social Welfare de la City University of New York.mahia.saracostti@uautonoma.cl 


\section{Introducción}

Tal como sucede con otras políticas públicas, para analizar el alcance de las políticas de infancia que se implementan en nuestro país, se vuelve de gran relevancia poner atención en el modo en que los gobiernos locales concretan los lineamientos generados a nivel central, y también la forma en que éstos generan sus propias políticas, de acuerdo al contexto particular que enfrentan (Cravaucuore et. al., sin año). Tomando en cuenta que los gobiernos locales son una instancia de prestación de servicios públicos muy próxima a la comunidad, es de alta relevancia conocer el tipo de políticas de infancia que se implementan en este nivel, $y$ analizar algunas causas que pueden incidir en las diferencias que se aprecien en este plano.

Considerando lo anterior, a continuación se presenta una revisión de los resultados obtenidos en un estudio acerca de las políticas de infancia y adolescencia desarrolladas por 45 gobiernos locales de Chile, que pone énfasis en revisar la relación de las condiciones contextuales que enfrentan estos municipios con su nivel de implementación de este tipo de políticas. Este análisis es valioso, pues permite cuestionar la tesis de que son exclusivamente las condiciones municipales las que determinan el nivel de implementación de determinadas políticas.

La información a partir de la que se efectúa este trabajo corresponde a una investigación desarrollada por los autores, producto de un convenio entre la Universidad Diego Portales (UDP) y la Asociación Chilena de Municipalidades (ACHM), destinado a generar las bases para la implementación en Chile del proyecto de "Comunas Amigas de la Infancia", impulsado por la propia ACHM.

El artículo se estructura en cuatro apartados: primero, se realiza una revisión de los lineamientos conceptuales que guían la elaboración y ejecución de políticas de infancia, sus implicancias para el trabajo de éstas en los gobiernos locales, y las consecuencias de las condiciones municipales en el nivel de implementación de dichas políticas. Posteriormente, se muestra la estrategia metodológica desarrollada para la recolección de información y análisis de la misma. En tercer lugar, se presentan algunos resultados de la investigación, a través de una descripción general del diagnóstico, la presentación multinivel entre el grado de implementación de políticas de infancia y la caracterización de las condiciones municipales, y los análisis estadísticos de correlación entre ambas variables. Finalmente, se presentarán las principales conclusiones surgidas a partir de los análisis efectuados.

\section{Referencias conceptuales}

A continuación se desarrollará una descripción de los principales aspectos conceptuales y teóricos relacionados con los ámbitos de interés para este estudio. En un primer momento, se abordarán los lineamientos generales de las políticas públicas de infancia y adolescencia, la manera en que éstas se expresan en gobiernos locales y la forma de gestión que en este nivel se ha desarrollado en Chile (Sistemas Locales 
de Protección de Derechos). En segundo lugar, se revisará la incidencia que tienen en las políticas de infancia la complejidad que presentan los contextos locales, y las condiciones con que cuentan los gobiernos municipales para desarrollar e implementar dichas políticas. Por último, se presentarán las categorías elaboradas para clasificar y orientar contextualizadamente los desafíos que surgen a cada municipio, de acuerdo a sus condiciones municipales y al nivel de implementación de políticas públicas que presentan.

\section{I.I Las políticas de Infancia}

a) Orientaciones actuales de las políticas de infancia y adolescencia:Vigencia de la Convención de Derechos del Niño.

En el año 1990, Chile ratificó la Convención de Derechos del Niño (CDN) (ONU, 1989), que constituye un tratado internacional jurídicamente vinculante, en el que participan 191 países pertenecientes a la Organización de Naciones Unidas. Esta convención ha instalado la visión del niño como un sujeto de derechos donde "los niños tienen un estatus igual a los adultos como miembros de la humanidad; no son propiedad de sus padres, productos del Estado, ni proyectos de futuro" (UNICEF \& UAM, 2004: 4).

De esta forma, esta perspectiva supone que los niños no deben ser entendidos como sujetos "en vías" de llegar a ser alguien. Al respecto, se plantea explícitamente que la necesidad de superar la mirada de "niños, niñas y adolescentes como sujetos incompletos, sometidos en su crianza y cuidado al arbitrio del adulto, despojado de sus plenos derechos como persona" (SENAME \& CIDPA, 2008: 27). Por lo tanto, la implementación de la CDN implica enfrentar barreras paradigmáticas importantes, para generar condiciones de posibilidad que permitan que niños y niñas se expresen y sean escuchados y considerados.

Esta nueva concepción relativa a quién es el niño ha resignificado el sentido que deben asumir las políticas públicas en la materia: hoy niños y niñas son sujetos activos de su propio desarrollo y su voz es fundamental a la hora de diseñar e implementar políticas destinadas a la promoción de sus derechos. En este punto, la CDN "hace hincapié en la capacidad de los niños para dejar de ser los beneficiarios pasivos de la protección y convertirse en destinatarios activos y comprometidos con sus derechos" (UNICEF, 2004: I5). Estas orientaciones requieren de un nuevo rol del Estado con la población infantil, que se centre en una perspectiva de derechos, con una mirada integral y multisectorial.

Así, "la Convención supera las instituciones del patronato, la tutela o los consejos tutelares del Estado, sujetos éstos a la doctrina de la situación irregular y a la concepción de los niños como objetos de protección; para ubicarlos en la doctrina de la protección integral, cuya concepción los reconoce como sujetos de derecho" (MIDEPLAN, 2000 en SENAME \& CIDPA, 2008: 29). 
b) La CDN en los gobiernos locales y las "Ciudades Amigas de la Infancia"

En el contexto antes descrito, los gobiernos municipales juegan un rol de alta relevancia en el proceso de diseño e implementación de las políticas dirigidas a la infancia:

Las autoridades locales se encuentran a la vanguardia del problema, pues como consecuencia de la tendencia hacia la urbanización y la descentralización de las tareas de gobierno, estas autoridades se han convertido, en muchos casos, en los principales agentes en materia de suministro de servicios básicos que afectan la vida de los niños (UNICEF, 2004: 25).

Aún cuando son los Estados Centrales quienes se hacen parte de esta Convención, y es sobre ellos que recaen buena parte de las obligaciones jurídicamente vinculantes de la CDN, no existirá un impacto potente de las políticas orientadas a la infancia y adolescencia si los municipios o gobiernos locales "no integran el enfoque de derecho y la doctrina de la protección integral de la infancia al conjunto de su política local" (SENAME \& CIDPA, 2008: 20). Esto implica que son estas instancias quienes deben asumir un rol activo como garantes del cumplimiento de las obligaciones que emanan de la CDN (Raczynski et. al., 2007).

Tomando en cuenta este desafío, diversos países han desarrollado iniciativas que promuevan el compromiso y la responsabilización de los municipios por estas materias. Destaca la iniciativa "Ciudades Amigas de la Infancia" (CAI) de la UNICEF, instancia que a través de la articulación de instituciones públicas, privadas y la sociedad civil, busca que los derechos de los niños y niñas ocupen el centro de la planificación municipal. Así, una CAI debe garantizar, entre otros, el derecho de los niño/ as a: tomar decisiones que influyan en su ciudad, participar en la vida familiar, social y comunitaria, recibir servicios básicos como salud y educación, ser protegido de la explotación, la violencia y el abuso, ser un ciudadano en condiciones de igualdad, con independencia de su origen étnico, religioso y socioeconómico, su género o su discapacidad (UNICEF et. al., sin año; Cillero, Sin año).

Esta iniciativa tiene como experiencia emblemática el caso español, donde existe un desarrollo amplio y fructífero de Ciudades Amigas de la Infancia. Gracias a la ayuda de UNICEF, se ha permitido la realización de concursos periódicos que permiten premiar las mejores prácticas municipales de promoción de derechos de niños, niñas y adolescentes (UNICEF et. al., sin Año). En latinoamericana, destaca el Proyecto "Alcaldes por la Infancia" de Brasil, que ha generado una red de intercambio de información entre gobiernos locales, y la creación del "Premio Alcaldes por la Infancia”, para dar visibilidad a las políticas municipales que consideran a la infancia como prioridad (Abrinq Foundation, sin año). 
c) Realidad Chilena: Sistemas Locales de Protección de Derechos (SLPD) de la infancia y adolescencia

En el caso chileno, y para implementar la CDN, el Servicio Nacional de Menores (SENAME) diseña un nuevo modelo orientado al desarrollo de sistemas locales que protejan los derechos de los niños, niñas y adolescentes. Así, en un esfuerzo conjunto con las municipalidades se crean las Oficinas de Protección de Derechos de la Infancia (OPD). Su creación, y la de otros programas de promoción y prevención instalados en los territorios, son parte del esfuerzo por potenciar los SLPD, definidos como:

... Conjunto de comunicaciones, vínculos y acciones colaborativas, que sobre la base de la Convención de los Derechos del Niño, se establecen entre actores comunitarios e institucionales, públicos y privados, que trabajan en infancia, con el fin de garantizar la protección y promoción integral de los derechos de los niños, niñas y adolescentes, en un territorio determinado (SENAME, 2006: 17).

De esta forma, y de manera conjunta con algunas municipalidades, se crean las OPD, las cuales tienen dos funciones principales: i) la gestión intersectorial y la articulación territorial para la protección y promoción de los derechos de la infancia, y ii) la protección de niños y niñas que sufren la vulneración de sus derechos, prestando ayuda sicológica, legal y social a ellos y sus familias.

Actualmente existen I05 OPD a lo largo del país, que se encuentran presentes en cerca de 170 municipios'. Esto permite que el SENAME amplíe la cobertura y participación en cada uno de estos territorios. Dicho de otro modo, las OPD buscan que la atención sea más adecuada y pertinente a los diversos contextos locales, a partir de una articulación directa con los actores institucionales y comunitarios relevantes de ser considerados en el diseño y ejecución de sus políticas.

Sin embargo, existen diversos estudios que ponen evidencia que en la práctica se ha realizado un trabajo segregado y no integral hacia la infancia (Raczynski et. al., 2007; Raczynski, 2006), desvinculando los derechos de los/as niños/as con sus necesidades. Debido a esto, el año 1999 el Estado Chileno promulga la "Política Nacional y el Plan de Acción Integrado a favor de la Infancia y Adolescencia 200 I-20I0”, que implicó una serie de reformas en distintos niveles, a fin de reorientar las políticas de infancia y adolescencia del país. Así, el Ministerio de Justicia, en conjunto con el SENAME dio inicio al proceso de "Reforma Integral al Sistema de Justicia y Protección de la Infancia y Adolescencia en Chile”, a fin de adecuar el marco legislativo al espíritu de la CDN. Por su parte, a partir del año 2000 el SENAME también se embarca en 
la tarea de reconfigurar su accionar, principalmente con "la creación de programas que respondan al nuevo paradigma de la Protección Integral” (SENAME, 2006: 3).

De este modo, se aprecia que no existe actualmente una política nacional que haya evaluado y reorientado las políticas públicas en esta área, así como el hecho de que las OPD tienen un alcance más "administrativo" que las CAI, en la medida en que no interpelan a los actores que definen las políticas comunales (alcaldes).

I.Il Municipios chilenos: condiciones e implicancias para las políticas de infancia y adolescencia

En las últimas décadas los municipios en Chile se han convertido en organismos centrales del desarrollo nacional. Considerados como un eje clave en la descentralización del país, han sido sustantivos en dar mayores y mejores respuestas a la población, y de acuerdo a ello, requieren modernizar y fortalecer su gestión para satisfacer la enorme responsabilidad que tienen frente a la ciudadanía (Matus, 2007: 10).

Estos aspectos muestran la necesidad de incorporar a los análisis el "reconocimiento de la diversidad de las comunidades que conviven en nuestro país y de las heterogéneas realidades de nuestro territorio y sus instituciones, es un elemento fundamental para el logro de una profunda descentralización y de una democracia fuerte y consolidada" (SUBDERE, 2005: 2).

De este modo, al hablar de políticas locales de infancia, esta heterogeneidad se manifiesta al menos en los siguientes elementos: nivel de implementación de estas políticas, recursos disponibles para diseñarlas, ejecutarlas y/o evaluarlas, necesidades y demandas de la población infantil y adolescente, etc. Por esto, tanto para el análisis de la implementación actual de políticas de infancia como para la promoción futura de estas, es necesario distinguir las diferentes realidades municipales, a fin de hacer pertinentes los diagnósticos y exigencias que se establezca a cada gobierno local. Al respecto, existen dos variables clave para comprender estas particularidades: i) la complejidad del entorno municipal, y ii) las condiciones con que cuenta el municipio para desarrollar una política de calidad.

\section{a) La complejidad del entorno municipal}

El proceso moderno de globalización y la ampliación de las barreras societales ha traído consigo una emergencia por la comprensión y el conocimiento de las múltiples dimensiones de la vida social (Castells, 1996). En este contexto, el concepto de complejidad ha tomado fuerza, pues permite incorporar las condiciones diferenciadas de la realidad al interior del análisis social.

En este sentido, se dice que la complejidad es una condición misma de las organizaciones y sistemas. Tal como indica Arriaga, la complejidad no debe ser "vista como un obstáculo ni una dificultad para la construcción de un sistema, sino que se constituye en la condición que hace posible al sistema" (Arriaga, 2003: 278). Esto implica que 
la noción de complejidad es una noción relacional, ya que un espacio se relaciona de manera compleja con otros espacios.

Aplicado al ámbito de los gobiernos locales, la definición entregada por Matus sobre complejidad señala que ésta es "entendida como las dificultades que los municipios tienen hoy para enfrentar los cambios en el sistemalentorno de sus respectivas comunas" (Matus, 2007:16). De este modo, para el caso específico de este estudio se entenderá por complejidad a:"Las condiciones del sistema/entorno municipal que pueden facilitar o dificultar el buen desarrollo de las políticas de infancia y adolescencia, tales como el nivel de pobreza o vulnerabilidad de la población, el nivel de escolaridad, la existencia de oferta educativa suficiente, etc.".

\section{b) Condiciones para la Calidad}

Por su parte, las condiciones para la calidad son definidas como "las condiciones existentes en cada municipio para brindar una mejor gestión, de modo que no es una indagación evaluativa sobre la calidad de la gestión, sino sobre las condiciones con que cuentan los municipios para realizarla" (Matus, 2007:16). En el caso de este estudio, se entenderán las condiciones para la calidad como: "Las capacidades instaladas en el municipio, ya sean humanas, materiales, de gestión, etc., que permiten (o dificultan) el buen desarrollo de una política de infancia y adolescencia".

Diversos investigadores (Horst \& Larroulet, 2003; Raczynski \& Serrano, 200I) han mostrado cómo, a pesar de los indudables avances en la administración municipal, aún persisten diversos nudos críticos en su accionar.

En general, los estudios reconocen que la inexistencia de modelos de gestión municipal, la carencia de profesionales idóneos, los problemas de gobernabilidad y la débil participación ciudadana como los principales problemas del desarrollo local chileno (Bosier, 2004). De acuerdo con lo anterior, es necesario "identificar dónde están las dificultades en la organización, para lo que se basa en evidencia, lo que permite introyectar procesos de mejoramiento constantes y profundos" (ChileCalidad, 2008: 24). De este modo, la diferencia entre complejidad del entorno municipal y condiciones para la calidad se observa en la siguiente figura:

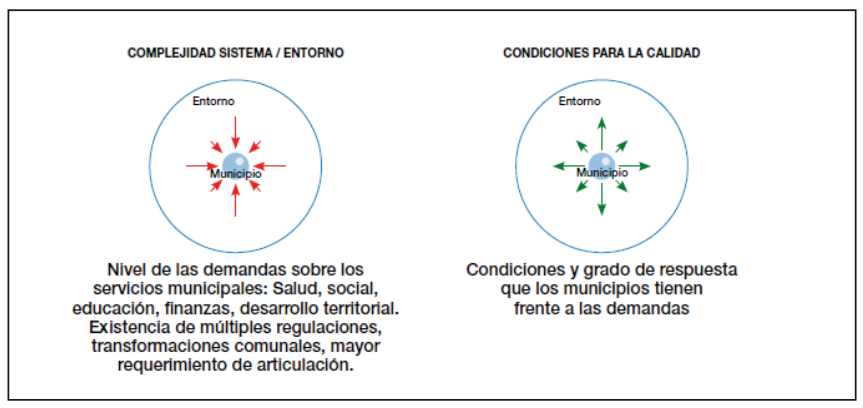

Fuente: Matus, 2007:18. 
c) Análisis relacional: Condiciones Municipales y Nivel de Implementación de las Políticas de Infancia y Adolescencia

A fin de relacionar la heterogeneidad existente en los municipios, expresada tanto en la complejidad de su entorno como en las condiciones con las que cuenta para ofrecer servicios de calidad; y los diferentes niveles de implementación de políticas de infancia que estas pueden presentar, el diagnóstico desarrollado generó una clasificación de los municipios en base a estos dos elementos.

La idea central es mostrar que existen posibilidades concretas de desarrollar una implementación de políticas de infancia, aún en espacios en los que las administraciones locales se encuentran limitadas por condiciones poco favorables. Con este objetivo, se presentan las siguientes categorías que emergen del cruce de estas variables, y que buscan dar cuenta de los diferentes niveles de exigencia que pueden ser requeridos a los municipios que conformen la experiencia chilena de la "Red de comunas Amigas de la Infancia”:

- Municipios para "Consolidación e Innovación" de políticas de infancia: Se trata de municipios que cuentan condiciones adecuadas (por ejemplo en términos de dotación de personal, recursos financieros, infraestructura, complejidad del entorno, etc. $)^{2}$, y que además poseen un nivel avanzado de implementación de políticas de infancia. Se les debe requerir consolidar sus resultados en los indicadores evaluados, $y$ desarrollar innovaciones en políticas de infancia que permitan maximizar la implementación de una perspectiva integral de derechos.

- Municipios para "Mejoras Significativas" de políticas de infancia: Se trata de municipios que si bien cuentan con condiciones de contexto adecuadas, presentan un bajo nivel de desarrollo e implementación de políticas de infancia. Se les debe requerir avances más significativos y prontos en esta materia.

- Municipios para "Afianzamiento y Proyección" de políticas de infancia: Se trata de municipios que no cuentan con condiciones de contexto adecuadas, pero que pese a eso poseen un buen desarrollo e implementación de políticas de infancia. Se les debe requerir el afianzamiento de las políticas de infancia y de la institucionalidad desarrollada, y la proyección de ambos aspectos que permita la generación de las mejoras que sean pertinentes, dado el contexto específico del municipio.

- Municipios para "Estructuración e Institucionalización” de políticas de infancia: Se trata de municipios que no cuentan con condiciones de contexto adecuadas, y que poseen un bajo nivel de desarrollo e implementación de políticas de

Es importante consignar que los autores reconocen el hecho de que prácticamente todos los municipios del país cuentan con recursos escasos ante la magnitud de los requerimientos a los que deben hacer frente. Considerando esto, se entiende por "adecuado" a las condiciones de aquellos municipios que, en comparación a otros gobiernos locales, se desenvuelven en un contexto más favorable, conforme a los criterios evaluados. 
infancia. Se les debe requerir que sistematicen sus programas de infancia, a fin de estructurar una política consistente hacia este sector de la población, cuestión que además debe ir acompañado de la institucionalización de los equipos, mecanismos y políticas desarrolladas.

De este modo, el siguiente esquema muestra de forma gráfica la clasificación presentada, así como los efectos esperados en los municipios de cada categoría con el impulso de la "Red de Comunas Amigas de la Infancia":

\section{Modelos de clasificación de Municipios}

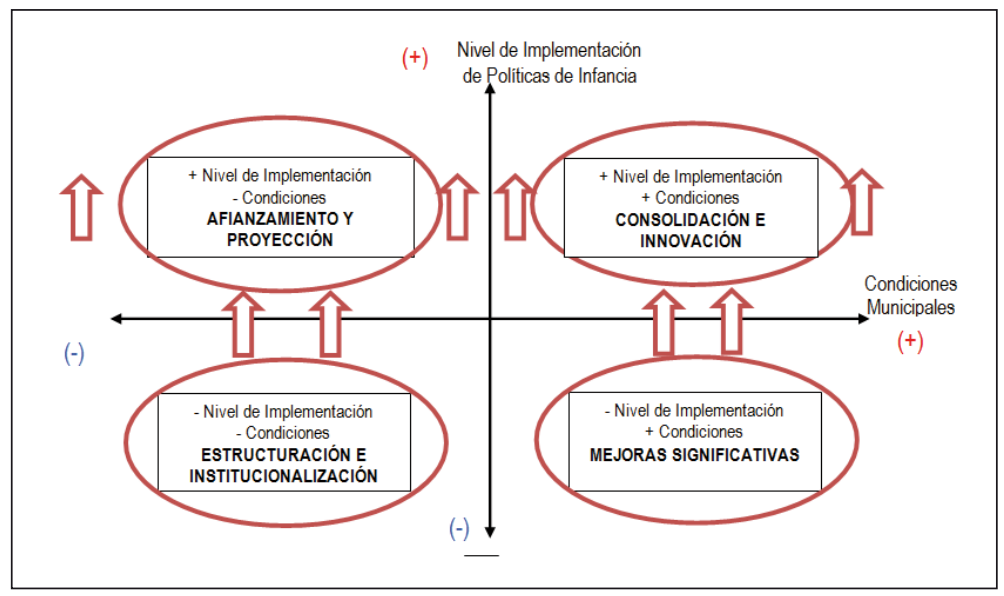

\section{Diseño metodológico.}

El siguiente apartado da cuenta de los principales aspectos metodológicos que se consideraron para el desarrollo de la investigación. En primer lugar, presenta una descripción general del instrumento generado para recolectar la información diagnóstica de las políticas de infancia implementadas a nivel local. En segundo lugar, se detallan los principales aspectos de la construcción del Índice de Implementación de Políticas de Infancia, y posteriormente del Índice de Condiciones Municipales. Finalmente, se realiza un análisis de consistencia, sensibilidad y capacidad explicativa de los índices.

\section{II.I Encuesta Nivel de Implementación de Políticas de Infancia}

Para la evaluación del nivel de implementación de políticas de infancia, se elaboró una encuesta especialmente diseñada para obtener información primaria respecto de nuestro tema de interés (Canales, 2006). Esta encuesta fue elaborada con apoyo de profesionales del Departamento de Protección de Derechos del SENAME, 
quienes colaboraron con esta investigación en la revisión de dicho instrumento, y además durante el proceso de contacto realizado a las comunas encuestadas.

Dada la amplitud territorial del espacio en el que debía implementarse la encuesta elaborada, y al hecho de que la información a recopilar con este instrumento requería la revisión de información de distintas fuentes por parte del personal municipal, se optó por desarrollar una encuesta de aplicación on line.

Este instrumentos contó con las siguientes dimensiones: i) Institucionalidad, ii) Redes, iii) Proyectos orientados a la infancia, iv) Política o plan general comunal para la infancia y adolescencia y; v) Recursos. La encuesta fue enviada al total de 90 comunas de las regiones de Valparaíso y Metropolitana, contando con 45 respuestas. La información fue entregada tanto por personal de la Dirección de Desarrollo Comunitario como por los Equipos de Infancia u OPD de cada comuna.

\section{II.II. Índice de Implementación de Políticas de Infancia}

Los datos recolectados con la encuesta implementada fueron utilizados para la construcción de un “Índice de Implementación de Políticas de Infancia”. El objetivo de este índice es realizar un segundo nivel de análisis de la información, mediante una clasificación de los municipios en torno a un indicador estandarizado respecto de su nivel de implementación de políticas de infancia. Las siguientes son las subdimensiones y variables de este índice, junto con la ponderación que cada una de ellas tuvo en el indicador generado.

Contenido y ponderaciones “Índice Implementación Políticas de lnfancia"

\begin{tabular}{|l|c|l|c|}
\hline DIMENSIONES & $\%$ & \multicolumn{1}{|c|}{ SUB DIMENSIÓN } & $\%$ \\
\hline \multirow{2}{*}{ Institucionalidad } & \multirow{2}{*}{$10 \%$} & $\begin{array}{l}\text { Instrumentos municipales que incorporan proyectos o } \\
\text { programas dirigidos a la infancia. }\end{array}$ & $50 \%$ \\
\cline { 3 - 4 } & & $\begin{array}{l}\text { Instrumentos municipales que incorporan la política o } \\
\text { plan comunal de infancia. }\end{array}$ & $50 \%$ \\
\hline \multirow{2}{*}{$\begin{array}{l}\text { Diagnóstico y Eva- } \\
\text { luación }\end{array}$} & \multirow{2}{*}{$10 \%$} & $\begin{array}{l}\text { Realización de diagnóstico sobre necesidades de la infan- } \\
\text { cia y adolescencia en la comuna. }\end{array}$ & $50 \%$ \\
\cline { 3 - 4 } & Evaluación de los programas/proyectos. & $50 \%$ \\
\hline $\begin{array}{l}\text { Proyectos /Progra- } \\
\text { mas para la Inf.y } \\
\text { Adolesc. }\end{array}$ & \multirow{2}{*}{$18 \%$} & Proyectos en ejecución y fuentes de financiamiento. & $40 \%$ \\
\cline { 3 - 4 } & Áreas que abordan los proyectos/programas. & $30 \%$ \\
\cline { 2 - 4 } & Lineamientos de los proyectos/programas. & $30 \%$ \\
\hline
\end{tabular}




\begin{tabular}{|l|l|l|l|}
\hline \multirow{4}{*}{$\begin{array}{l}\text { Política o Plan Ge- } \\
\text { neral Comunal de } \\
\text { Inf.y Adolesc. }\end{array}$} & \multirow{2}{*}{$18 \%$} & $\begin{array}{l}\text { Existencia de una política o plan general y si está en } \\
\text { ejecución. }\end{array}$ & $40 \%$ \\
\cline { 3 - 4 } & & Áreas que aborda el Plan o Política comunal de infancia. & $15 \%$ \\
\cline { 3 - 4 } & & Lineamientos del Plan o Política comunal de infancia. & $15 \%$ \\
\cline { 3 - 4 } & & Antigüedad del Plan o Política comunal de infancia. & $15 \%$ \\
\cline { 3 - 4 } & Estado de implementación de Plan o Política de infancia. & $15 \%$ \\
\hline \multirow{2}{*}{ 5. Redes } & \multirow{2}{*}{ 6. Participación } & \multirow{2}{*}{$\begin{array}{l}\text { Identificación de redes, convenios, alianzas y mesas de } \\
\text { trabajo, y sus fuentes de financiamiento }\end{array}$} & $100 \%$ \\
\hline \multirow{2}{*}{ 7. Recursos } & $\begin{array}{l}\text { Participación de actores externos al equipo de infancia en } \\
\text { diagnóstico }\end{array}$ & $50 \%$ \\
\cline { 3 - 4 } & \multirow{2}{*}{$\begin{array}{l}\text { Participación de actores externos al equipo de infancia en } \\
\text { la elaboración de la política o plan comunal de infancia }\end{array}$} & $50 \%$ \\
\hline & Recursos humanos & $60 \%$ \\
\hline & Recursos monetarios & $40 \%$ \\
\hline
\end{tabular}

\section{II.III Índice de Condiciones Municipales}

Para profundizar el análisis del nivel de implementación de políticas de infancia, se construyó el "Índice de Condiciones Municipales" a fin de contrastar el nivel de desarrollo de estas políticas con la realidad del contexto de cada municipio estudiado. Este índice se elaboró en base a la sistematización y análisis de datos secundarios disponibles para estos municipios ${ }^{3}$. Se consideraron aspectos que pudieran responder tanto a las condiciones de calidad y complejidad municipal, tal como se presenta a continuación ${ }^{4}$. Las siguientes son las subdimenciones e indicadores considerados, junto con su ponderación respectiva para la construcción de dicho indicador:

\section{Dimensiones, subdimensiones y ponderaciones “Índice de Condicio- nes Municipales"}




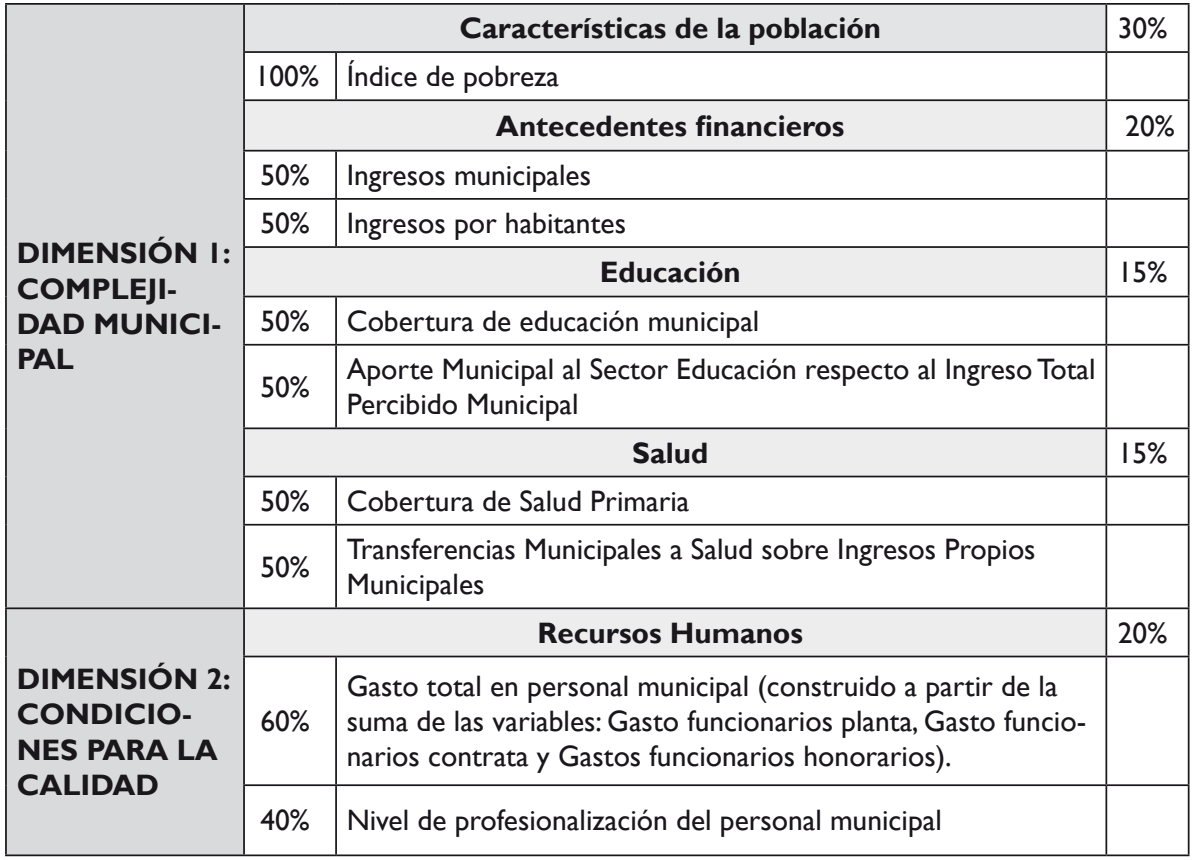

II.IV.Análisis de consistencia y sensibilidad de los Índices

Existe una multiplicidad de formas y métodos de análisis estadístico, que permiten evaluar la consistencia, capacidad de discriminación y potencia de los índices (OECD, 2008; Vermunt \& Magidson, 2005). En este caso, buscaremos responder a dos interrogantes: ¿Cuánto de la variabilidad de las variables e indicadores originales se "pierde" en la construcción de los índices? y ¿De qué manera los indicadores utilizados en la construcción del índice se relacionan?

Para responder a la primera pregunta, se construirá una regresión múltiple mediante OLS que permita evaluar la capacidad explicativa de los índices con respecto a las variables originales utilizadas. Esto implica que utilizaremos la siguiente ecuación:

$$
Y=\beta_{0}+\beta_{1} x_{1}+\beta_{2} x_{2} \ldots+\text { ? }
$$

donde $Y$ corresponde al resultado de los índices construidos, $\beta_{0}$ a una constante, $\beta_{1} \chi_{1}, \beta_{2} \chi_{2}, \ldots$ a las variables originales utilizadas para la construcción de los índices $y$ a un error.

En el caso del índice de condiciones municipales, los resultados indican que el nivel de explicación global del modelo es cerca del $80 \%$ de la varianza del índice, lo que indica que el proceso de recodificación y estandarización permitió conservar la variabilidad de las variables originales. Para explicar este índice, son estadísticamente 
significativos el nivel de pobreza, el gasto total en personas del municipio y el aporte que el municipio realiza en educación.

Por otra parte, los resultados respecto del índice de nivel de implementación indican que las variables originales explican más del $95 \%$ de los resultados del índice. Esto implica que el índice logra capturar casi totalmente las diferencias originales de las comunas en cuanto al nivel de implementación de las políticas de infancias. En este caso, son estadísticamente significativas la cantidad de instrumentos municipales que incorporan proyectos o programas, el contar con un diagnóstico de infancia, el número de programas de infancia, la existencia de una política comunal de infancia, la cantidad de actores que participan en la elaboración del plan, y el financiamiento externo.

Por otro lado, para evaluar de qué manera los distintos indicadores del índice se relacionaban, se decidió realizar una matriz de correlación, ${ }^{5}$ que permitiera evaluar la relación existente entre los índices, bajo el supuesto de que si existen correlaciones muy altas, estas variables estarían midiendo aspectos relativamente parecidos (indicando la posibilidad de que existan problemas de colinealidad entre las variables).

En el caso del índice de condiciones municipales, se pudo comprobar que, en general, no existen correlaciones altas entre los factores. La excepción es la relación entre el gasto en personal y los ingresos municipales. Es posible hipotetizar entre una relación entre estas dos variables, bajo el entendido de que el ingreso municipal de la comuna podría estar determinando el gasto en personal que esta tiene.

Por otra parte, el índice de nivel de implementación de políticas de infancia y adolescencia presenta mayores niveles de correlación, especialmente en torno a dos dimensiones: i) Diagnóstico y evaluación y ii) Política o Plan general comunal de infancia y adolescencia. En términos generales, las altas correlaciones están relacionadas con otros indicadores de la misma área, mostrando la existencia de importantes causalidades entre las variables. En sí mismo, esto no constituye un problema, dado que el peso fue asignado a cada área y posteriormente a cada variable, por lo que este efecto de correlación se estaría controlando en la medición final del índice.

\section{Resultados de investigación}

La exposición de los resultados de este trabajo parte con los principales hallazgos del diagnóstico de implementación de políticas de infancia en las comunas encuestadas. Posteriormente muestra un análisis multidimensional, considerando el cruce entre el nivel de implementación de las políticas de infancia y adolescencia y las condiciones municipales. Finalmente se exponen algunos resultados explicativos, evaluando el impacto e influencia de distintos factores en el nivel de implementación de las políticas de infancia y adolescencia en cada municipio.

Se decidió una evaluación por esta vía frente a otros análisis (análisis de componentes principales, análisis factorial, etc.) debido a que estas incluían condiciones del tamaño muestral y número de observaciones que no permitían que el análisis desarrollado fuera conclusivo. 


\section{I. Nivel de implementación de políticas de infancia y adolescencia: Una breve descripción.}

A continuación se presentan los resultados respecto del nivel de implementación de las políticas de infancia y adolescencia. Como se mencionó, el análisis se realizó para el 50\% de las comunas de la Región Metropolitana y deValparaíso (45 de 90) ${ }^{6}$.

\section{a) Programas implementados de Infancia y Adolescencia}

Un primer elemento respecto a los programas implementados en este ámbito tiene que ver con el agente responsable de los programas declarados por el municipio. Como se aprecia en el gráfico I, los programas corresponden mayoritariamente a políticas del gobierno central, donde la administración comunal actúa sólo como implementador y/o agente coordinador.

\section{Gráfico I: Programas de Infancia y Adolescencia implementados por los municipios}

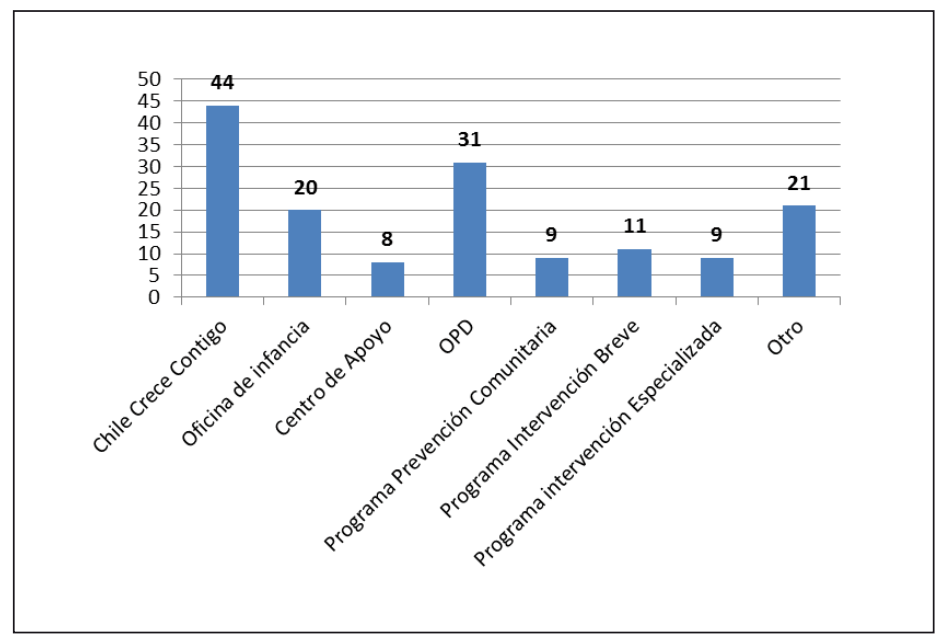

Fuente: Elaboración propia, datos Encuesta de Implementación de Políticas de infancia

Como se puede apreciar, casi la totalidad de las comunas implementan el programa Chile Crece Contigo, siendo también relevantes el desarrollo de OPDs u Oficinas de Infancia. Bastante por detrás aparecen programas propiamente municipales, como Programas de Intervención Breve, Programa de Intervención Especializada,

6 De los 45 municipios analizados, un 66,6\% (30) corresponde a municipios de la Región Metropolitana, mientras que el restante 33,3\% (15) corresponde a municipios de la Región de Valparaíso. 
Programa de Prevención Comunitaria o programas específicos asociados a determinadas problemáticas (consumo de drogas, maltrato infantil). Esto contrasta con la alta diversidad temática de los programas, aún cuando existe un notorio énfasis por la instalación de políticas de educación y salud ${ }^{7}$, lo que implica la existencia de un amplio alcance temático de los programas implementados.

En términos de la orientación de los programas implementados, también es posible observar una alta diversidad. Los municipios indican que sus programas tienen como objetivo desarrollar instancias de sensibilización, promoción y difusión de los derechos de niños/as y adolescentes, y la articulación y fortalecimiento del trabajo en red.

También es destacable que distintos programas busquen explícitamente mejorar la institucionalidad comunal en el área y acciones de capacitación, pudiendo ser un aporte en el fortalecimiento orgánico de la comuna respecto a este tema. Adicionalmente, es importante destacar que, mientras algunas comunas reconocen no tener desarrollados procesos de evaluación, otros indican que tienen incorporada la evaluación como un proceso continuo de la gestión comunal ${ }^{8}$.

Finalmente, es importante mencionar que un grupo relevante de los municipios (cerca del 30\%) afirma no realizar diagnósticos sobre la realidad comunal del área de infancia y adolescencia. En las comunas en que este procedimiento sí se efectúa, en su desarrollo participan principalmente funcionarios municipales de este ámbito, constatándose una baja participación de la comunidad y de otras instituciones públicas locales.

\section{b) Planes Comunales de Infancia y Adolescencia}

Un segundo aspecto analizado dice relación con las orientaciones consideradas por los municipios que cuentan con Políticas o Planes comunales de infancia y adolescencia. Dentro de los municipios que cuentan con este instrumento, los municipios reconocen una multiplicidad de áreas abordadas, tal como se muestra el gráfico que aparece a continuación:

7 Del total de 45 encuestas, los datos muestran que las áreas más abordadas por los proyectos desarrollados en los municipios son Educación y Salud, seguidas por Apoyo Psicosocial, Familia y Deporte. Las áreas menos reconocidas como focos de intervención son Arte/Cultura y Prevención del Delito.

8 Un número considerable de comunas ( 15 de 45) no responde a esta pregunta. 5 comunas manifiestan haber realizado una evaluación a 0 o el $10 \%$ de sus programas, 7 a un 50 ० $60 \%$ y 18 dicen haber evaluado el total o casi el total de sus programas $(90-100 \%)$. 


\section{Gráfico 2: Áreas abordadas por el Plan o Política Comunal de infan- cia y adolescencia}

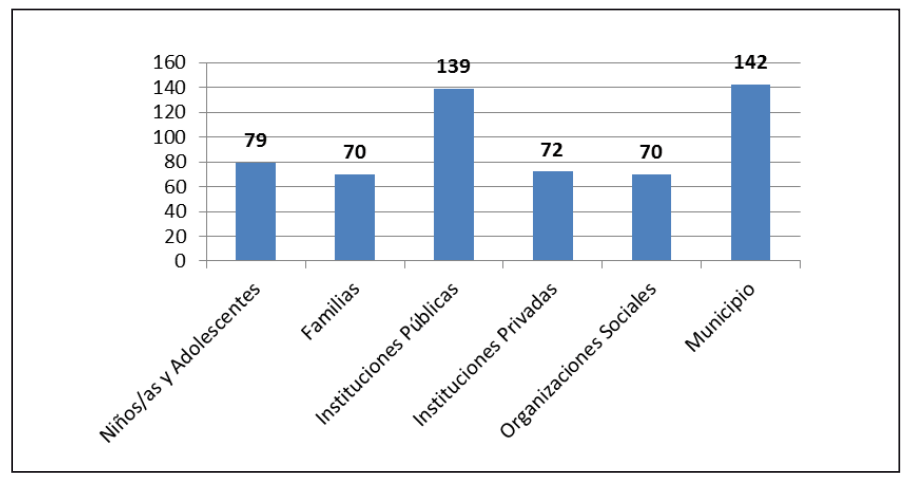

Fuente: Elaboración propia, datos Encuesta de Implementación de Políticas de infancia

Como puede observarse, se reiteran entre las 4 temáticas más abordadas las de educación, salud y apoyo psicosocial. Esto es fundamental pues indica una priorización de los municipios hacia la construcción de políticas de infancia entendidas bajo tres elementos principales: El educativo, el biológico y el social. Sin embargo, en segundo lugar se aprecia el área "Familia", lo que muestra un enfoque más amplio de entendimiento de los actores que son sujetos de estas políticas.

Otro elemento relevante tiene que ver con los actores externos al municipio que son considerados para la elaboración de este Plan o Política comunal de Infancia y Adolescencia. Al respecto, es importante mencionar que en general los municipios dicen incorporar a una importante cantidad de actores en la elaboración de su plan, vislumbrando la existencia de una colaboración virtuosa entre la municipalidad y otros actores sociales. Ahora bien, la mayoría de los municipios que cuentan con un plan manifiestan que las instituciones públicas y los niños y adolescentes son parte de esta elaboración, mientras que en un segundo plano se encuentran las organizaciones sociales y distintas organizaciones no gubernamentales (ONGs).

c) Construcción e instalación de redes para el trabajo en Infancia y Adolescencia

Un aspecto relevante del análisis de las políticas y programas que efectúan los municipios dice relación con las redes y vinculaciones que éstos establecen con actores locales, para dar cuenta de los desafíos que se enfrentan en esta materia. En este sentido, es importante mencionar que los municipios desarrollan una multiplicidad de vinculaciones con el entorno. Mientras la mayoría de los municipios dicen poseer redes (75 declaradas en total), también una parte importante reconoce otros tipos de vinculaciones, como convenios (40), mesas de trabajo (26) y alianzas (7). 
Ahora bien, cuando se analiza cuáles son los actores locales del entorno municipal que forman parte de estas vinculaciones, se puede indicar la importancia de agentes internos del sector municipal, tal como se aprecia en el gráfico:

Gráfico 3: Menciones de participación de actores externos al área municipal de infancia y adolescencia en vinculaciones del área

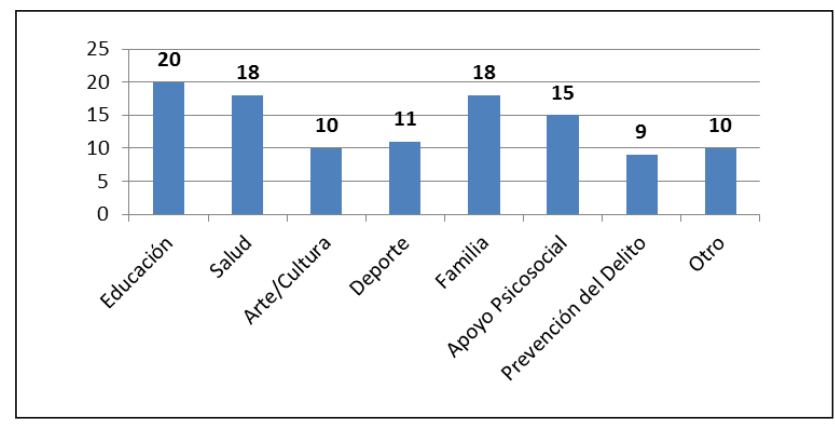

Fuente: Elaboración propia, datos Encuesta de Implementación de Políticas de infancia

Como se observa, el mayor número de participaciones lo tienen otros departamentos del municipio (142) y otras instituciones públicas. De esta forma, se aprecia una primacía de consideración de otros actores del sector público, por sobre la participación de miembros de la comunidad como niños/as y adolescentes (79), familias (70) y organizaciones sociales (70).

d) Recursos Municipales para temáticas de Infancia y Adolescencia

En cuanto a elementos indicativos de los recursos humanos y monetarios disponibles por los equipos de infancia para su trabajo, un primer elemento refiere al número de profesionales que se desempeña en políticas y/o programas de infancia, y al área de formación disciplinaria al que pertenecen. La mayor parte de los profesionales que trabajan en infancia y adolescencia provienen del área de las ciencias sociales (trabajadores o asistentes sociales, psicólogos, sociólogos, etc.), los que duplican a la siguiente área (ciencias de la salud), además de un número significativo de profesionales que provienen de "otras” áreas.

Gráfico 4: Promedio y promedio corregido comunal de profesionales con dedicación a temas de infancia y adolescencia, por área de formación profesional 


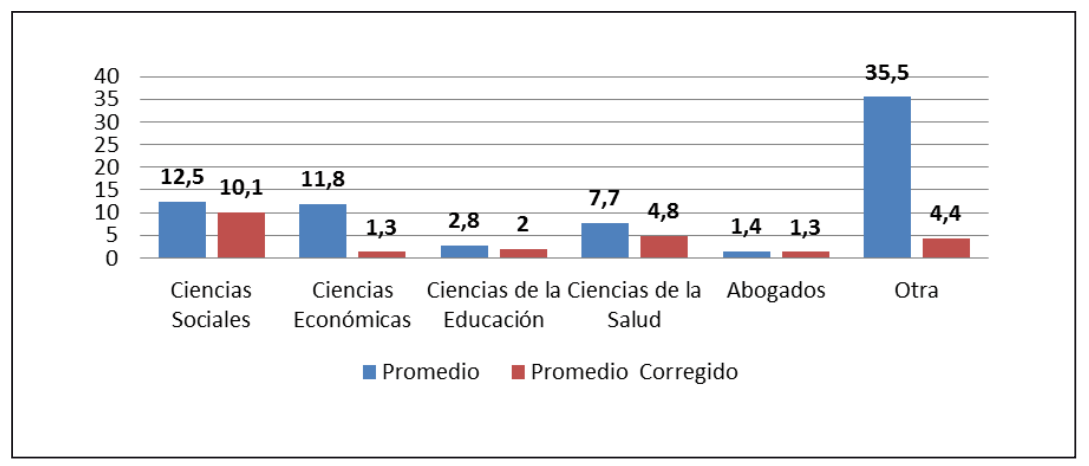

Fuente: Elaboración propia, datos Encuesta de Implementación de Políticas de infancia

Se indica el promedio corregido ya que en cada área de formación existía una comuna con un número muy alto de profesionales, por lo que se optó por eliminar del cálculo a la comuna con más profesionales por área. Considerando esa cifra, se observa que los municipios tienen, en promedio, cerca de 25 profesionales dedicados a temas de infancia, número elevado por un grupo pequeño de municipios con una amplia planta de profesionales para el área.

Las cifras muestran la existencia de 28 comunas con profesionales del área de las ciencias sociales especializados en materias de infancia y/o adolescencia. Le siguen los municipios con abogados especializados en el área (16). Estas cifras, pueden ser indicativas del tipo de trabajo que ejecutan en esta materia los municipios, principalmente asociados a procesos judiciales y a acciones remediales (con psicólogos, y trabajadores y asistentes sociales).

Junto con esto, se recolectó información respecto de las principales fuentes de financiamiento declaradas por los municipios para la implementación de programas de infancia y adolescencia.Al respecto, las fuentes casi exclusivas de financiamiento corresponden a dineros puestos por el municipio, o directamente por el gobierno central. Esto muestra la escasa vinculación existente con otro tipo de instituciones que permita sumar otros recursos a los delimitados por los montos entregados por dichas instituciones.

\section{e) Institucionalización de las políticas de infancia y adolescencia}

Por último, se abordarán aspectos que tienen que ver con la institucionalidad de los municipios respecto de las políticas de infancia. Al respecto, es relevante analizar en qué medida los programas de infancia y/o adolescencia son incorporados en los instrumentos de gestión comunal, pudiendo entenderse como una medida de la capacidad del municipio de desarrollar institucionalmente la política de infancia. 


\section{Gráfico 5: Incorporación de programas de infancia y/o adolescencia en instrumentos de gestión comunal}

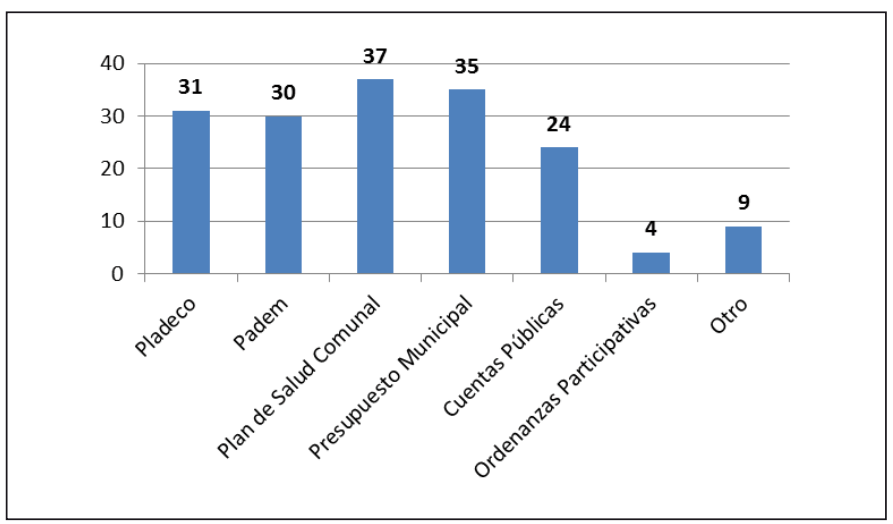

Fuente: Elaboración propia, datos Encuesta de Implementación de Políticas de infancia

Otra forma de evaluar el nivel de institucionalización que existe en cada comuna, refiere a la existencia de planes o políticas comunales de infancia y adolescencia. Al respecto, sólo 20 municipios (44,4\%) dicen tener un plan específico para este sector, mientras 25 municipios, correspondiente al 55,5\% de los municipios encuestados, dice no contar con este instrumento.

Esto da cuenta de la existencia de una importante limitante para implementar estas políticas con una perspectiva estratégica, de manera sistematizada y conocida por los actores que en ella deben trabajar ${ }^{9}$. Esto se vuelve aún más relevante, cuando se diagnostica que sólo 13 de los 20 municipios que informaron tener este Plan o Política se encuentran en ejecución. De estos, la gran mayoría (16) de las Políticas y Planes de Infancia y Adolescencia cuentan con una antigüedad no superior a los 4 años, tal como se aprecia en el siguiente gráfico:

Esto se ve reforzado por el bajo nivel de interacción existente entre los planes de infancia y otros instrumentos municipales. Cuando se analizan los datos, se puede observar que del total de 20 municipios que cuentan con este Plan o Política, la mitad los considera en sus PLADECO, 9 en sus Cuentas Públicas y 8 en el Presupuesto Municipal; mientras que en la planificación sectorial, sólo en 5 los consideran en el PADEM y en los Planes de Salud. 


\section{Gráfico 6: Años de desarrollo de Plan o Política de Infancia y Ado- lescencia}

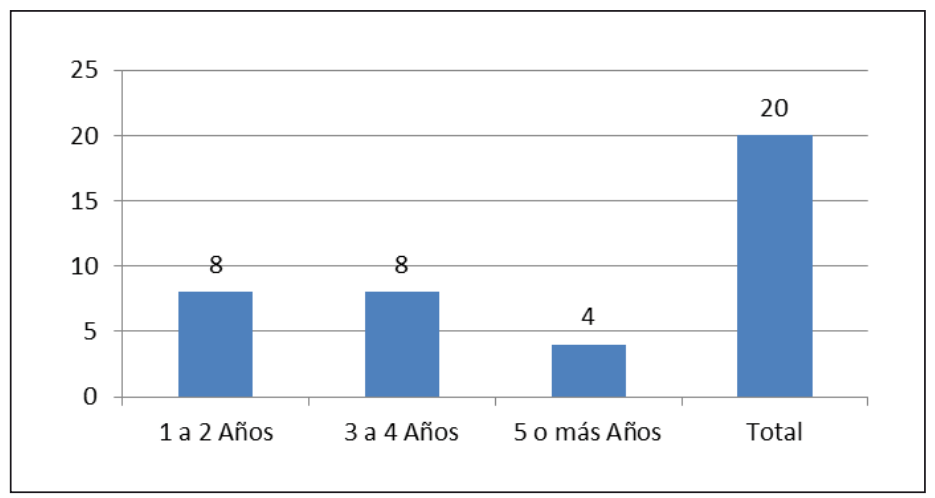

Fuente: Elaboración propia, datos Encuesta de Implementación de Políticas de infancia

Esto nos podría estar indicando que, en términos de la institucionalización de la gestión municipal para el desarrollo de una política de infancia y adolescencia, los municipios chilenos se encuentran recién en un proceso de estructuración y consolidación, marcado por la promoción y puesta en marcha de una serie de instrumentos y políticas que permitan enmarcar el trabajo sectorial.

\section{III.II. La clasificación de municipios: Un análisis multidimensional}

Junto con dar cuenta de los resultados respecto del nivel de implementación de las políticas de infancia y adolescencia en los municipios, es fundamental revelar los resultados de la construcción de los índices, tanto respecto de las condiciones municipales como del nivel de implementación de las políticas de infancia y adolescencia.

Respecto al Índice de Condiciones Municipales, se construyó con una variabilidad entre 5,00 y I,00 donde un mayor puntaje indicaría mejores condiciones municipales para la implementación de la política estudiada. En términos empíricos, el promedio de los municipios fue de 2,93, donde el mayor puntaje obtenido fue de 4, 10 (Providencia) mientras que el menor puntaje fue de I,85 (Limache) ${ }^{10}$, dando cuenta de una importante diferencia en términos de las condiciones que tienen los municipios para poder desarrollar políticas de infancia y adolescencia.

Respecto del Índice de Políticas de Infancia, se construyó con la misma variabilidad que el anterior, buscando generar una sistematización de la información recopilada, estandarizando los resultados y permitiendo su comparabilidad. En términos empíricos, el puntaje promedio fue de 3,05, siendo el mayor puntaje de 4,92 (Peñalolén) y el menor puntaje fue de I, I0 (Putaendo), reflejando también una importante

10 Adicionalmente, dos comunas no pudieron ser incorporadas en el índice (Juan Fernandez e Isla de Pascua) debido a que no se tuvo la información necesaria. 
heterogeneidad con respecto a este índice. Considerando lo anterior, fue posible construir la clasificación de los municipios, a partir del cruce de los resultados obtenidos en ambos índices. El siguiente mapa da cuenta de dichos resultados, mostrando las categorías en las que cada municipio queda incluido:

\section{Mapa de clasificación comunal: "Índice de condiciones Municipales” - "Índice Nivel de Implementación Políticas de Infancia”}

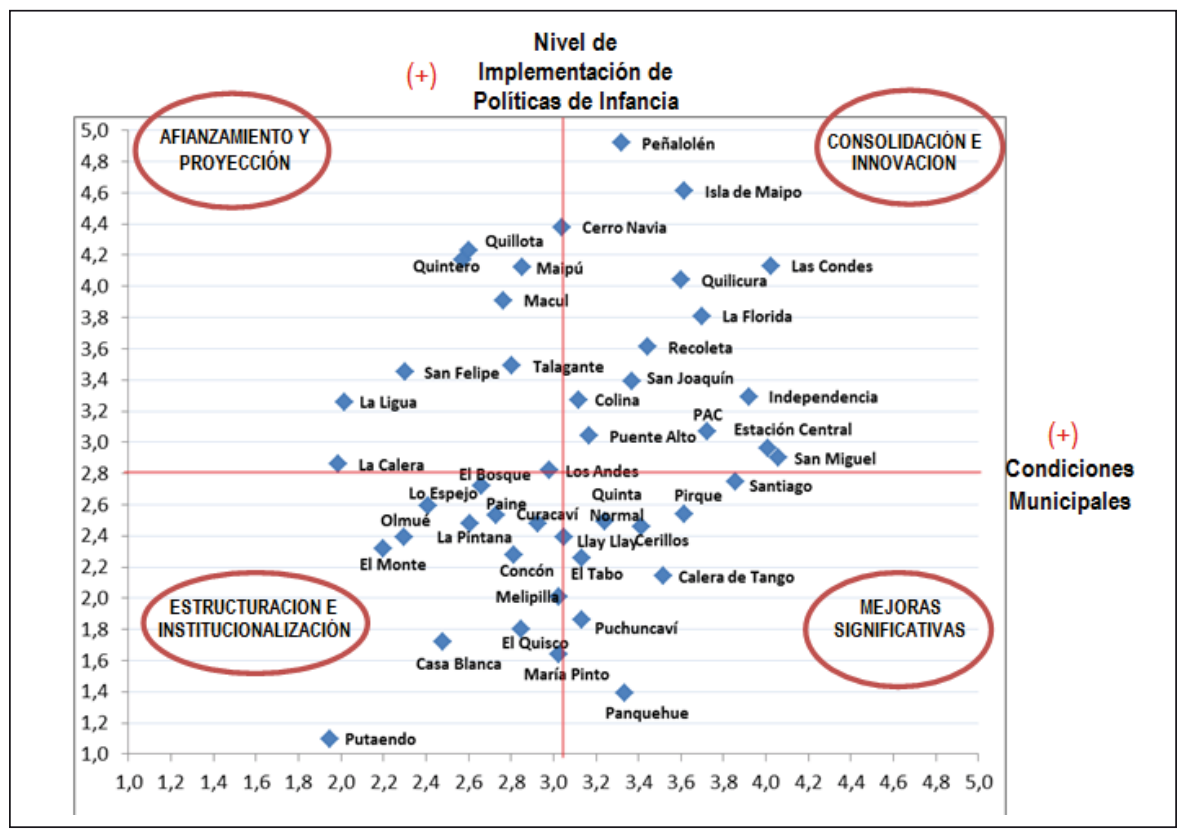

Fuente: Elaboración propia, datos Encuesta de Implementación de Políticas de infancia y www.simin.cl

La división de cada una de las variables consideradas se trazó en la mediana de la distribución de cada índice. De este modo, la comuna número 23 en cada índice marcó el nivel de división (Los Andes en el caso del Índice Nivel de Implementación de Políticas de Infancia, y Cerro Navia en el caso del Índice de Condiciones Municipales).

Considerando lo anterior, a continuación se presenta una tabla con la clasificación de las comunas que se encuentran en cada una de las categorías construidas. En el caso de las comunas que se encuentran en la mediana de cada índice, estas fueron incluidas en la categoría superior en dicho índice. 


\section{Listado comunas por categoría de clasificación}

\begin{tabular}{|c|c|c|c|c|c|c|c|}
\hline $\mathbf{N}^{\circ}$ & $\begin{array}{l}\text { I. CONSOLIDA- } \\
\text { CIÓN E INNO- } \\
\text { VACIÓN }\end{array}$ & $\mathbf{N}^{\circ}$ & $\begin{array}{l}\text { 2.AFIANZ.Y } \\
\text { PROYECCIÓN }\end{array}$ & $\mathbf{N}^{\circ}$ & $\begin{array}{l}\text { 3. MEJORAS } \\
\text { SIGNIFICA- } \\
\text { TIVAS }\end{array}$ & $\mathbf{N}^{\circ}$ & $\begin{array}{l}\text { 4. ESTRUC- } \\
\text { TURACIÓN E } \\
\text { INSTITUCIO- } \\
\text { NALIZACIÓN }\end{array}$ \\
\hline I & Peñalolén & I & Quillota & I & Santiago & I & El Bosque \\
\hline 2 & Isla de Maipo & 2 & Quintero & 2 & Pirque & 2 & Lo Espejo \\
\hline 3 & Cerro Navia & 3 & Maipú & 3 & Quinta Normal & 3 & Paine \\
\hline 4 & Las Condes & 4 & Macul & 4 & Cerrillos & 4 & La Pintana \\
\hline 5 & Quilicura & 5 & Talagante & 5 & Llay Llay & 5 & Curacaví \\
\hline 6 & La Florida & 6 & San Felipe & 6 & El Tabo & 6 & Olmué \\
\hline 7 & Recoleta & 7 & La Ligua & 7 & Calera de Tango & 7 & El Monte \\
\hline 8 & San Joaquín & 8 & La Calera & 8 & Puchuncaví & 8 & Concón \\
\hline 9 & Independencia & 9 & Los Andes & 9 & Panquehue & 9 & Melipilla \\
\hline 10 & Colina & & & & & 10 & El Quisco \\
\hline II & P.Aguirre Cerda & & & & & II & Casa Blanca \\
\hline 12 & Puente Alto & & & & & 12 & María Pinto \\
\hline 13 & Estación Central & & & & & 13 & Putaendo \\
\hline 14 & San Miguel & & & & & & \\
\hline
\end{tabular}

Fuente: Elaboración propia, datos Encuesta de Implementación de Políticas de infancia

Como se aprecia, las categorías que presentan más comunas corresponden a los extremos: 14 comunas se encuentran con buenas condiciones y un buen nivel de implementación de políticas de infancia (Consolidación e Innovación), y I 3 presentan condiciones más adversas y un nivel más bajo de implementación de políticas de infancia (Estructuración e Institucionalización). Adicionalmente, es significativo notar que estas últimas comunas en su mayoría corresponden a municipios de características rurales.

A partir de esto, es importante mencionar que, en términos generales, se confirma nuestra hipótesis inicial: Existen comunas que, teniendo las mismas condiciones municipales, presentan niveles muy diferentes de implementación de políticas de infancia. De todas formas, se aprecia una relación entre ambos índices, en el sentido de que los niveles de implementación de políticas de infancia aumentan progresivamente en la medida en que aumenta el índice de condiciones municipales.

III. III. Análisis explicativo: Factores relevantes en la implementación de políticas de infancia y adolescencia.

Un primer aspecto de los análisis explicativos implica realizar una evaluación de la correlación entre el índice de condiciones municipales y el índice de nivel de implementación de políticas de infancia y adolescencia. De existir una alta correlación 
entre ambos índices, podríamos suponer que, para mejorar las políticas de infancia y adolescencia, sería necesario cambiar sus condiciones municipales.

Para realizar esta evaluación, optamos por dos caminos distintos: Una primera forma es simplemente analizar la correlación entre ambos índices. El resultado de esta medición arrojó una correlación de 0,24 dando luces de la existencia de una cierta relación, pero siendo esta no muy intensa". Una segunda forma de realizar esta evaluación es a través de una regresión OLS, que incorpore como variable dependiente al índice de políticas de infancia y como variable independiente al índice de condiciones municipales. A continuación se presenta una tabla con la estimación:

\section{Estimación regresión: Índice políticas de infancia sobre índice condi- ciones municipales}

\begin{tabular}{|l|c|c|c|c|c|c|}
\hline Índice pol. Inf. & Coeficiente & Error est. & Test T & $\mathbf{P}>|\mathbf{t}|$ & \multicolumn{2}{|c|}{$\begin{array}{c}\text { 95\% intervalo } \\
\text { de confianza }\end{array}$} \\
\hline Indice cond. mun & $0.3808 \mathrm{I} 7 \mathrm{I}$ & 0.2346288 & 1.62 & 0.112 & -0.0923 & 0.8539 \\
\hline Constante & $1.77336 \mathrm{I}$ & 0.7276868 & 1.44 & 0.019 & 0.3058 & 3.2408 \\
\hline
\end{tabular}

Como podemos observar, los resultados son categóricos: No existe una relación estadísticamente significativa entre los dos índices. Esto implica que los coeficientes del índice de implementación de políticas de infancia no están siendo afectados por el nivel de condiciones comunales.

Sin embargo, esto no implica que no existan algunas variables municipales, hayan sido consideradas o no por el modelo, que puedan estar afectando la política de infancia. Para evaluar esta posibilidad, es necesario realizar una nueva especificación al modelo de regresión, donde la variable dependiente (índice de políticas de infancia y adolescencia) sea evaluada en función de una multiplicidad de variables relacionadas con las características de los municipios.

En términos genéricos, podemos estructurar el modelo así:

$$
Y=\beta \text { cons }+\beta_{1} X_{1}+\beta_{2} X_{2}+\text { ? }
$$

donde $\chi_{1}$ son los coeficientes asociados a características estructurales del municipio' ${ }^{12}$ y $\chi_{2}$ esté relacionado con coeficientes de las características utilizadas en la construcción del índice de condiciones municipales. Los resultados del modelo general y de los coeficientes asociados, se presentan a continuación:

"En términos generales, existe un consenso que correlaciones sobre 0,4 implica que ambas variables están fuertemente relacionadas.

12 Entenderemos por características estructurales municipales aquellas características del municipio no relacionadas necesariamente con "mejores" o "peores" condiciones municipales, sino con la estructura del espacio territorial, como la población, región en la que se ubica y grado de ruralidad. 
Modelo de regresión: Indicadores de condiciones municipales e indicadores estructurales

\begin{tabular}{|c|c|c|c|c|c|c|}
\hline Obs. & \multicolumn{2}{|l|}{31} & \multicolumn{2}{|c|}{ R- cuadrado } & \multicolumn{2}{|c|}{0.8042} \\
\hline$F(21,9)$ & \multicolumn{2}{|l|}{1.76} & \multicolumn{2}{|c|}{ R - cuadrado aj. } & \multicolumn{2}{|c|}{0.3472} \\
\hline Prob > F & \multicolumn{2}{|c|}{0.1923} & \multicolumn{2}{|c|}{ Root MSE } & \multirow{2}{*}{\multicolumn{2}{|c|}{$\begin{array}{c}0.72959 \\
\begin{array}{c}95 \% \text { intervalo d } \\
\text { confianza }\end{array}\end{array}$}} \\
\hline Índice pol. Inf. & \multirow{2}{*}{\begin{tabular}{|c|} 
Coeficiente \\
0.016688
\end{tabular}} & Error est. & \multirow{2}{*}{$\begin{array}{c}\text { Test T } \\
0.02\end{array}$} & \multirow{2}{*}{$\frac{P>|t|}{0.982}$} & & \\
\hline Región & & 0.712035 & & & -1.5940 & 1.62742 \\
\hline Población & 0.000074 & $0.00007 \mid$ & 0.01 & 0.338 & -0.0000 & 0.00009 \\
\hline Pobreza & -0.060132 & 0.054800 & -1.10 & 0.301 & -0.1841 & 0.06383 \\
\hline Ruralidad & -0.022973 & 0.016830 & -1.37 & 0.205 & -0.0610 & 0.01509 \\
\hline ingreso_mun & -0.000002 & 0.000001 & -0.19 & 0.852 & -0.0000 & 0.00000 \\
\hline presup_hab & 0.001322 & 0.010207 & 0.13 & 0.900 & -0.0217 & $0.0244 I$ \\
\hline fondo_comun & 0.025784 & 0.002226 & 1.16 & 0.277 & -0.0245 & 0.07614 \\
\hline n_escuelas & -0.000422 & 0.050812 & -0.01 & 0.994 & -0.1175 & 0.21924 \\
\hline asist_escuelas & 0.506433 & $0.07444 I$ & 0.68 & 0.512 & -0.1153 & 0.11452 \\
\hline reten_basica & 2.172583 & 1.403854 & 1.55 & 0.156 & -1.0031 & 5.34832 \\
\hline reten_media & -0.513532 & 0.085993 & -0.60 & 0.565 & -0.2458 & 0.14317 \\
\hline cober_media & 0.003595 & 0.019895 & 0.18 & 0.861 & -0.0414 & 0.04860 \\
\hline aport_educacion & 0.041782 & 0.052631 & 0.79 & 0.448 & -0.7727 & 0.16084 \\
\hline cober_salud & 0.005644 & 0.015799 & 0.36 & 0.729 & -0.0300 & 0.04138 \\
\hline n_consultorios & -0.382604 & 0.261086 & -1.47 & 0.177 & -0.9732 & 0.20801 \\
\hline tras_salud & $-0.0273 \mid 4$ & 0.095731 & -0.29 & 0.782 & -0.2438 & 0.18924 \\
\hline gasto_planta & 0.000000 & 0.000001 & 0.27 & 0.797 & -0.0000 & 0.00000 \\
\hline gasto_contrato & -0.000000 & 0.000004 & -0.93 & 0.378 & -0.0000 & 0.00000 \\
\hline gasto_honorario & 0.000014 & 0.000000 & 1.86 & 0.096 & -0.0000 & 0.00003 \\
\hline profesionalizacion & 0.021719 & 0.021486 & 1.01 & 0.339 & 0.02688 & 0.07032 \\
\hline Constante & -5.038279 & 7.417219 & -0.68 & 0.514 & -21.817 & 11.7406 \\
\hline
\end{tabular}

Como se puede observar, en general, las variables que dan cuenta de las condiciones municipales no están relacionadas con la política de infancia. Esto comprueba lo anteriormente dicho, ya que se esperaría que si no hay correlación con el índice tampoco lo hubiera con las variables de condiciones utilizadas.

Ahora bien, respecto de las variables estructurales incorporadas, en términos generales tampoco son fundamentales para explicar el nivel de implementación de las políticas de infancia y adolescencia, aún cuando su importancia es mayor a los anteriores grupos de variables. De hecho, existe una relación significativamente estadística (al $5 \%$ ) en la ruralidad como variable explicativa del nivel de implementación de política, y también un efecto moderado de la cantidad de población. Considerado esto, es claro que, en términos generales, las políticas de infancia y adolescencia no están 
condicionadas a las características del municipio, y por ello, es el municipio mismo el mayor responsable por el desarrollo de este tipo de estas políticas.

Finalmente, parece fundamental evaluar si la institucionalización de determinadas acciones orientadas a potenciar las políticas de infancia y adolescencia en los municipios tiene un impacto en el nivel de implementación de políticas. Como vimos, durante los últimos años la acción más potente ha sido la instalación de Oficinas de Protección de Derechos (OPDs) en el municipio. ¿Han contribuido efectivamente al desarrollo de una política de infancia y adolescencia en el nivel local? Esta es, precisamente, la pregunta que buscaremos responder. Para ello, seguiremos dos caminos distintos: Por una parte, evaluaremos (mediante un modelo de regresión) si el índice de implementación de políticas de infancia se ve explicado por la existencia de OPDs en el municipio. Posteriormente, evaluaremos si existe alguna diferencia relevante entre aquellos municipios que tienen OPDs y aquellos que no tienen.

Para la primera aproximación, entenderemos que la variable independiente es la existencia o no de OPDs (variable dummy), mientras que la variable dependiente será el nivel de implementación de la política de infancia y adolescencia. Los resultados del modelo se presentan a continuación:

\section{Estimación regresión: Índice políticas de infancia sobre existencia OPDs}

\begin{tabular}{|l|c|c|c|c|c|c|}
\hline Índice pol. Inf. & Coeficiente & Error est. & Test T & \multicolumn{2}{|c|}{$\mathbf{P}|\mathbf{t}|$} & \multicolumn{2}{|c|}{$\begin{array}{c}\text { 95\% intervalo de } \\
\text { confianza }\end{array}$} \\
\hline Opd & 1.356578 & 0.863882 & 1.57 & 0.151 & -0.5976 & 0.3785 \\
\hline Constante & $1.77336 \mathrm{I}$ & 0.7276868 & 1.44 & 0.019 & 0.3058 & 3.2408 \\
\hline
\end{tabular}

Como puede observarse, si bien existe una relación positiva y alta entre la tenencia de OPD y el índice de implementación de política de infancia, la potencia de la relación es débil, pues no es estadísticamente significativa para un $95 \%$ de confianza.

Sin embargo, cuando realizamos la segunda evaluación, encontramos algunas diferencias, pues sí existe una diferencia significativa entre los distintos grupos de variables:Aquellos que tienen OPD y aquellos que no tienen. Para ello, se aplicó un test de comparación de medias:

Test de comparación de medias:Tenencia o no de OPDs

\begin{tabular}{|l|c|c|c|c|c|c|}
\hline \multicolumn{1}{|c|}{ Grupo } & Obs & Media & Error & Desviación & \multicolumn{2}{c|}{$\begin{array}{c}95 \% \text { intervalo de } \\
\text { confianza }\end{array}$} \\
\hline 0 & 12 & $2.2334 I 7$ & 0.249382 & 0.863886 & 1.6845 & 2.7823 \\
\hline $\mathrm{I}$ & 33 & 3.190015 & 0.134860 & 0.774716 & 2.9154 & 3.4648 \\
\hline Ambos & 45 & 2.935022 & 0.133844 & 0.897853 & 2.6652 & 3.2047 \\
\hline Diferencia & & -0.957348 & 0.269166 & & -1.4665 & -0.4139 \\
\hline
\end{tabular}


Como se evidencia, existe una importante diferencia entre ambos grupos, ya que, en promedio, aquellos municipios que tienen OPD tienen casi I punto más en el índice de nivel de implementación de políticas de infancia y adolescencia, siendo esta diferencia estadísticamente significativa. Esto nos podría estar diciendo que, si bien el tener o no OPD no es un factor explicativo del nivel de implementación de la política, su existencia si es un factor catalizador que podría estar permitiendo procesos de institucionalización, desarrollo de planes y programas y fortalecimiento de redes municipales.

\section{Conclusiones}

Un primer nivel de conclusiones se encuentra dado por la mirada diagnóstica realizada a los datos reportados por la encuesta aplicada. Al respecto, una primera observación relevante dice relación con la constatación de que los programas implementados a nivel local corresponden mayoritariamente a políticas diseñadas en el nivel central, destacando la amplia cobertura del programa Chile Crece Contigo. Junto con eso, sólo 20 de las 45 comunas encuestadas cuenta con un plan comunal de infancia, y de estos, sólo 13 se encuentran en implementación. Por esto, podemos concluir que el nivel de desarrollo que alcanzan estas políticas desde los gobiernos locales es bajo. De todas formas, el hecho de que buena parte de los planes comunales de infancia hayan sido elaborados hace pocos años, o estén ahora en ese proceso, revela que el área de infancia se encuentra en una etapa de incipiente desarrollo a nivel municipal.

En cuanto a la alineación de los programas y políticas implementadas por los municipios encuestados, tenemos que la mayoría se focaliza en las áreas de salud y educación.Asimismo, la vinculación con actores externos se encuentra principalmente centrada en representantes de otros organismos públicos, más que en la consideración de representantes de la comunidad, o a los niños, niñas y adolescentes de cada comuna. De esta forma, se aprecia que existe un amplio espacio para potenciar aspectos como el abordaje integral de las políticas de infancia, y el incentivo a la participación infantil, orientaciones de alta relevancia para la CDN.

Ahora bien, cuando se analizan los resultados a la luz de las condiciones municipales, se visualizan distintos elementos relevantes. Por una parte, es clara la existencia de desiguales niveles de políticas de infancia, a niveles semejantes de condiciones municipales. De todas formas, en términos generales, la dispersión muestra que las categorías extremas (aquellas que relacionan niveles similares de implementación de políticas y condiciones municipales), son las que agrupan la mayor cantidad de comunas.

Esto indica que, en general, existe un margen de intervención municipal para la mejora del accionar de los gobiernos locales respecto de las políticas de infancia que implementan, en la medida en que se impulsen instancias que las promuevan como área prioritaria de su quehacer comunal. Junto con esto, permite detectar municipios que, considerando su nivel de implementación de políticas de infancia y condiciones municipales, puedan ser visualizados como fuente de buenas prácticas que permitan 
el desarrollo de acciones más eficientes y eficaces. Esta es, claro está, una veta potente para futuras investigaciones.

Esto cobra aún más importancia cuando se constata que, en términos estadísticos, el nivel de implementación de políticas de infancia y adolescencia no se encuentra afectado por el nivel de condiciones municipales, aún cuando algunas variables (ruralidad, población) si podrían estar afectando el desarrollo de estas políticas.

De este hallazgo, es posible extraer dos grandes conclusiones: Por una parte, que es el municipio el mayor responsable del nivel de implementación de políticas de infancia y adolescencia, y que desde su propia capacidad y posibilidad es posible realizar mejoras sustanciales para la calidad de los niños y niñas de la comuna. Esto implica otorgarle a la acción diaria del municipio un rol catalizador en la gestión, desarrollo y promoción de políticas integrales que permitan entender a los niños como sujetos de derechos. En el caso de las políticas de infancia, esto se vuelve aún más fundamental, considerando la proximidad que tienen estas instancias con la comunidad, y la importancia de las prestaciones que tienen bajo su responsabilidad.

Junto con esto, parece fundamental recalcar la necesidad de profundizar los análisis para evaluar el rol de las OPD en la implementación de políticas de infancia local. Como observamos, la existencia de OPD se relaciona positivamente con mayores niveles de implementación de políticas de infancia y adolescencia. Muy probablemente, estos resultados sean explicados por la mayor disponibilidad profesional en estas estructuras, y una mayor sistematización de las políticas realizadas, por lo que profundizar estudios que permitan explicar estas conexiones se erige como una tarea primordial.

\section{Referencias}

Abrinq Foundation (Sin año). Projeto Prefeito Amigo da Criança. Disponible en www. fundabrinq.org.br

Arriaga, Emilio (2003). La teoría de Niklas Luhmann. Centro de Innovación, Desarrollo e Investigación Educativa (CIDE). Universidad Autónoma del Estado de México.

Bosier, Sergio (2004). Desarrollo territorial y descentralización. Revista EURE PUC $N^{\circ}$ 90. Santiago.

Canales, Manuel (editor) (2006). Metodología de la investigación social. LOM. Chile.

Castells, Manuel (1996). La era de la información: Economía, sociedad y cultura, Tomo I: La sociedad red, Alianza Editorial, Madrid, España.

ChileCalidad (2008). Mejorando la gestión de los servicios públicos: Contribución de los modelos de excelencia. Gobierno de Chile. Santiago.

Cillero Bruñol, Miguel. (1998) El interés superior del niño en el marco de la Convención Internacional de los Derechos del Niño en García Méndez, Emilio. Beloff, Mary. (comp.), Infancia, ley y democracia en América Latina análisis crítico del panorama legislativo en el marco de la Convención Internacional sobre los derechos del niño (1990-1998), Ed.Temis/Desalma, Colombia.

Cravaucuore, llari, Villar (Sin año). La articulación en la gestión municipal. Actores y políticas. Universidad Nacional de Quilmes. 
Gobierno de Chile (2000). Política Nacional a favor de la infancia y la adolescencia 200I-20I0.

Horst, Bettina - Larroulet, Cristián (2003). Descentralización: aún queda mucho por hacer. Libertad y Desarrollo. Informe Económico N 143.

Matus, Teresa (2007). Reforma Municipal en la Mira. Identificando los municipios prioritarios en la RM: Complejidad Comunal versus condiciones para la calidad de la gestión municipal. Expansiva, Observatorio de Ciudades de la Universidad Católica y Escuela de Trabajo Social de la PUC.

OCDE (2008). Handbook on constructing compositive indicators. Methodology and user guide. Organisation for Economic Co-Operation And Development and Europpean Union. Disponible en <http://www.oecd.org/dataoecd/37/42/42495745.pdf>

ONU (1989). Convención sobre los Derechos del Niño. <www.ohchr.org>

Raczynski, Dagmar (2006). Política de infancia Temprana en Chile: Condicionantes del desarrollo de los niños. Revista En foco, Número 77, año 2006.

Raczinsky, Dagmar y Serrano, Marcela (200I). Descentralización. Nudos críticos. Corporación de Investigaciones Económicas para Latinoamérica -CIEPLAN- y Asesorías para el Desarrollo S.A.

Raczynski, Dagmar; Bedergal, Paula; Ferrer Juan Carlos; Margotta, Paula; Besomi, Dino y García Cristian (2007). Política de Infancia en el Nivel Local: Requerimientos y Aportes de la Gestión de Información, en Ignacio Irarrázabal, Elena Puga, Rosario Palacios, Anita Justiniano (eds): Camino al Bicentenario. Propuestas para Chile. Instituto de Políticas Públicas. Pontificia Universidad Católica de Chile. Santiago.

SENAME (2006). Sistemas Locales de Protección de Derechos de la Infancia-adolescencia: Una aproximación conceptual y de aplicación práctica. Departamento de Protección de Derechos.

SENAME - CIDPA. (2008) ¿Enfoque de derechos o enfoque de necesidades? Modelo de gestión para el desarrollo de un sistema local de protección de derechos de la infancia y adolescencia. SENAME - CIDPA.

SUBDERE (2005). Tipología: herramienta base para el reconocimiento de la diversidad comunal-municipal. División de Políticas y Estudios, Departamento de Estudios Municipales - SUBDERE.

UNICEF (2004). Ciudades para la Niñez. Los derechos de la Infancia, la pobreza y la administración urbana. UNICEF.

UNICEF - Comité español \& FEMP \& Ministerio del Trabajo y Asuntos Sociales, España (Sin Año). Experiencia en Buenas Prácticas. Ciudades Amigas de la Infancia. I Certamen sobre derechos de la Infancia. Ministerio del Trabajo y Asuntos Sociales, España.

UNICEF - Comité español \& Universidad Autónoma de Madrid (2004). Guía de Buenas Prácticas. Sobre planes y programas de infancia en el ámbito municipal español. Vermunt J.K. and Magidson J. (2005), Factor Analysis with categorical indicators:A comparison between traditional and latent class approaches. En A.Van der Ark, M.A. Croon and K. Sijtsma (eds), New Developments in Categorical Data Analysis for the Social and Behavioral Sciences, 4I-62. Mahwah: Erlbaum. 